\title{
Comparison of different base flow separation methods in a lowland catchment
}

\author{
A. L. Gonzales ${ }^{1}$, J. Nonner ${ }^{1}$, J. Heijkers ${ }^{2}$, and S. Uhlenbrook ${ }^{1,3}$ \\ ${ }^{1}$ UNESCO-IHE, Department of water engineering, P.O. Box 3015, 2601 DA Delft, The Netherlands \\ ${ }^{2}$ Hoogheemraadschap de Stichtse Rijnlanden - HDSR, P.O. Box 550, 3990 GJ Houten, The Netherlands \\ ${ }^{3}$ Delft University of Technology, Water Resources Section, P.O. Box 5048, 2600 GA Delft, The Netherlands \\ Received: 11 March 2009 - Published in Hydrol. Earth Syst. Sci. Discuss.: 27 April 2009 \\ Revised: 18 September 2009 - Accepted: 14 October 2009 - Published: 4 November 2009
}

\begin{abstract}
Assessment of water resources available in different storages and moving along different pathways in a catchment is important for its optimal use and protection, and also for the prediction of floods and low flows. Moreover, understanding of the runoff generation processes is essential for assessing the impacts of climate and land use changes on the hydrological response of a catchment. Many methods for base flow separation exist, but hardly one focuses on the specific behaviour of temperate lowland areas. This paper presents the results of a base flow separation study carried out in a lowland area in the Netherlands. In this study, field observations of precipitation, groundwater and surface water levels and discharges, together with tracer analysis are used to understand the runoff generation processes in the catchment. Several tracer and non-tracer based base flow separation methods were applied to the discharge time series, and their results are compared.

The results show that groundwater levels react fast to precipitation events in this lowland area with shallow groundwater tables. Moreover, a good correlation was found between groundwater levels and discharges suggesting that most of the measured discharge also during floods comes from groundwater storage. It was estimated using tracer hydrological approaches that approximately $90 \%$ of the total discharge is groundwater displaced by event water mainly infiltrating in the northern part of the catchment, and only the remaining $10 \%$ is surface runoff. The impact of remote recharge causing displacement of near channel groundwater during floods could also be motivated with hydraulic approximations. The results show further that when base flow separation is meant to identify groundwater contributions to
\end{abstract}

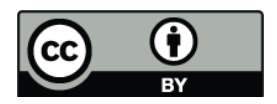

Correspondence to: A. L. Gonzales (arpadgon@hotmail.com) stream flow, process based methods (e.g. the rating curve method; Kliner and Knezek, 1974) are more reliable than other simple non-tracer based methods. Also, the recursive filtering method (proposed by Eckhardt, 2005) can be calibrated well using the results of tracer investigation giving good results. Consequently, non-tracer based base flow separation methods that can be validated for some events may provide a powerful tool for groundwater assessment or model calibration/validation in lowland areas.

\section{Introduction}

Understanding runoff generation processes, i.e. source areas, pathways and retention times, is important for the prediction of water quantities, including floods and low flows (base flows), and water quality in a catchment (e.g. Bonell, 1998; Uhlenbrook, 2006; Eckhardt, 2008). However, these processes continue to be difficult to quantify and conceptualize (McDonnell and Tanaka, 2001; Uhlenbrook and Hoeg, 2003) and the direct measurement of each discharge component, in a continuous way and at a sufficient number of locations is practically impossible (e.g. Tardy et al., 2004). The accurate analysis of water flow pathways from rainfall to streams is also needed for the optimal protection of surface and groundwater resources (e.g. Wenninger et al., 2004). Understanding of the runoff generation processes is also essential for assessing the impacts of changes (e.g. land use changes, climate change) on the hydrological response of a catchment (e.g. Uhlenbrook et al., 2008).

In many catchments, base flow is an important component of stream flow and, therefore, base flow separations have been widely studied and have a long history in the science of hydrology (Hall, 1968; Tallaksen, 1995). Base flow

Published by Copernicus Publications on behalf of the European Geosciences Union. 
separation methods can be divided in two main groups: nontracer-based and tracer-based separation methods. However, most of the studies focused on mountainous catchments, and little attention has been given to lowland areas and areas that have been strongly modified by man. Thus, in this study we will focus on such a lowland study area.

\subsection{Non tracer based base flow separation}

The first base flow separation methods focused on the analysis of the recession or depletion curves (e.g. Linsley et al., 1975; Szilagyi and Parlange, 1998) and they are capable of identifying the point where direct runoff (presumably surface runoff) finishes but they do not try to reconstruct the temporal variable base flow hydrograph during floods (Dingman, 2002). Later, the first filtering base flow separation methods were developed to standardize the graphical base flow separation methods (see also methodological section below): fixed interval, sliding interval and local minimum methods (Pettyjhon and Henning, 1979; Sloto and Crouse, 1996). Basically, these methods take the minimum values of the hydrograph within a pre-defined interval by following different criteria and connect them. The discharge under the constructed line is defined as base flow accordingly. More recent filtering methods assume that base flow, associated as it is with discharge from groundwater storage, produces the long wave responses of the hydrograph. Hence, low pass filtering of the hydrograph can be used to separate base flow (Eckhardt, 2005, 2008). Other base flow separation methods use the unit hydrograph method (e.g. Su, 1995). Here, the base flow is determined by fitting a unit hydrograph model with information from the recession limbs of the hydrograph and extrapolating it backwards. Another group of methods for base flow separation are the envelope and rating curve methods (Kliner and Knezek, 1974; Sellinger, 1996; Holko et al., 2002), which assume that a close relation exists between groundwater levels and stream flows during recession periods due to the hydraulic connection between the stream and aquifer. Therefore, observed groundwater levels are used to calculate base flow contributions based on previously defined relationships between groundwater levels and stream flows.

\subsection{Tracer-based base flow separation}

Hydrograph separations using hydrochemical tracers and environmental isotopes offer the possibility to gain a better understanding of the runoff generation processes (e.g. Bonell, 1998). For example, the use of natural tracers demonstrated that the retention of water in small catchments can be very long (e.g. Kirchner et al., 2000; McGuire and McDonnell, 2006). However, how and where the water is stored for so long in these catchments, while the hydrodynamic reaction during rain events can be very quick (cf. "hydrological paradox": Kirchner, 2003) is not completely understood.
This type of hydrograph separation is based on a mass balance approach, which assumes that the composition or chemical signature of water coming from various sources is constant and unique (different from each other) and that conservation of mass applies to the water quantities and water quality including conservative mixing of different water components (e.g. Weiler et al., 1999; Uhlenbrook and Hoeg, 2003). However, relatively large uncertainties may be present in the quantification of the runoff components due to a number of factors (e.g. Joerin et al., 2002). Some of these uncertainties are the product of tracer analyses and discharge measurements, intra-storm variability of isotopic concentration, elevation effect on the isotopic composition of rain, chemical reactions during runoff formation and the mixing of components, and spatial heterogeneity of tracer concentrations (see Uhlenbrook and Hoeg, 2003, for further discussion). Even though some of these uncertainties can be reduced by the use of transfer function methods (e.g. Weiler et al., 2003), the assumption of a constant and uniform signature for every component is often fulfilled within short intervals (e.g. within an event). Then, tracer based hydrograph separations can provide valuable information about the groundwater contributions to stream flow. However, little experience with this technique exists for low land areas.

\subsection{Objectives}

The objectives of this paper are (i) to compare different approaches for base flow separation in a lowland area, (ii) to demonstrate how the application of different methods in conjunction with additional experimental investigation can lead to a better understanding of the runoff generation processes, and (iii) to discuss the applicability of different base flow separation methods in lowland areas. The study was carried out in a typical lowland area at Langbroekerwetering in the Netherlands.

\section{Material and methods}

\subsection{Study area}

The study area is located in the central part of The Netherlands, in the province of Utrecht (Fig. 1). The Langbroekerwetering area is limited by the rivers Neder Rijn in the southeast and the Kromme Rijn towards the southwest. In the North, the area is bounded by an ice pushed ridge called the Utrechtse Heuvelrug (topographic divide). The surface of the study area is $51.7 \mathrm{~km}^{2}$.

The climate in the Langbroekerwetering area is humid temperate, with mild winters because of the strong influence of the Gulf Stream. The monthly average temperature varies between $2.6^{\circ} \mathrm{C}$ in January and $17.2^{\circ} \mathrm{C}$ in July. The mean annual rainfall in the study area amounts to $800 \mathrm{~mm}$, with a relatively high inter-annual variation and a moderate variation of the monthly rainfall within a year. The average rainfall 


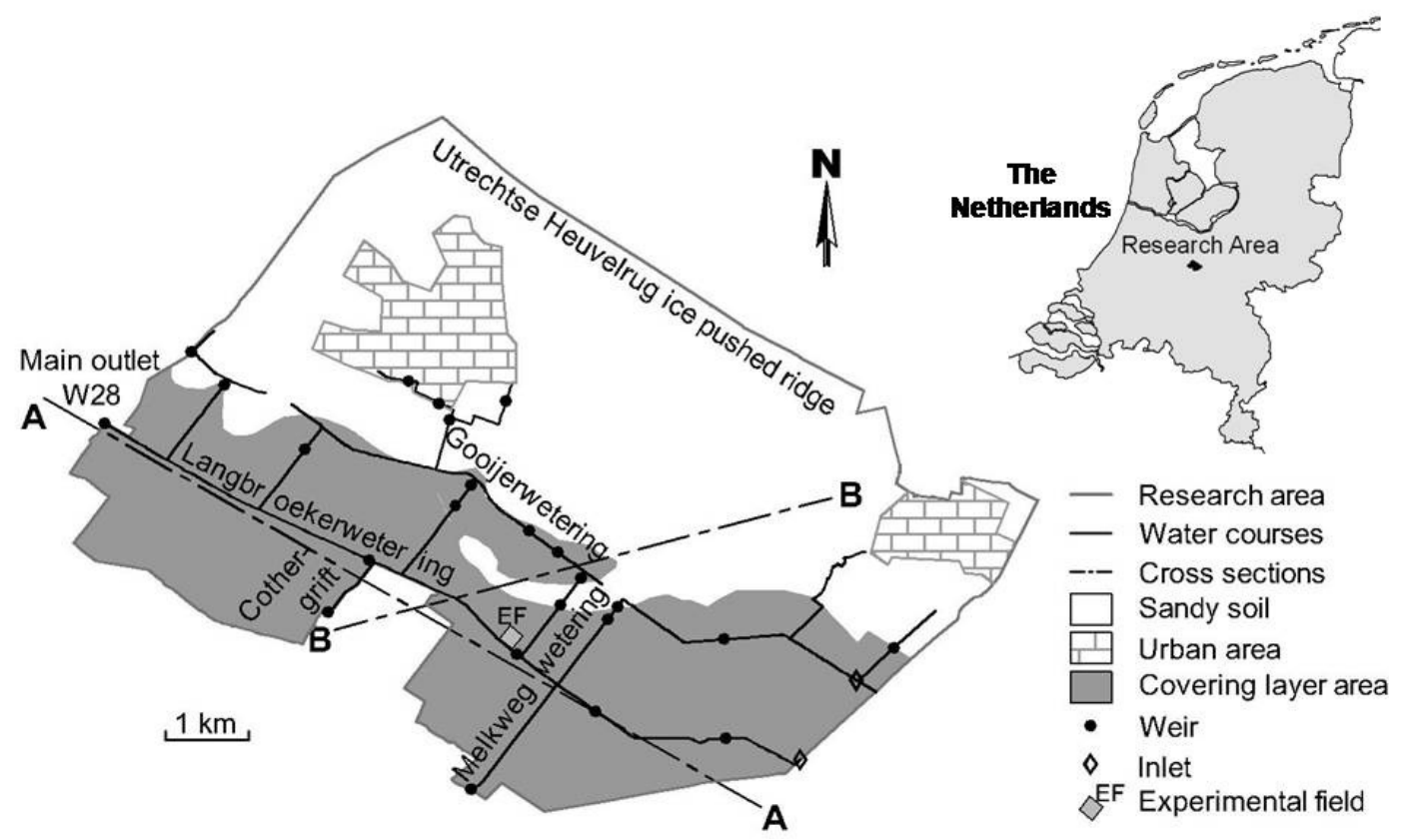

Fig. 1. The research area Langbroekerwetering, located in the center of The Netherlands.

amount in April is $46.5 \mathrm{~mm}$ (the driest month) and $80 \mathrm{~mm}$ in December (the wettest month). The mean annual potential evapotranspiration has been estimated at about $500 \mathrm{~mm}$ based on daily potential evapotranspiration data using the Penman-Monteith approach (Huang, 2007).

The highest area of the catchment is located at the Utrechtse Heuvelrug, an ice pushed ridge of about $60 \mathrm{~m}$. The ridge is characterized by sandy permeable soils. In this area infiltration and recharge of groundwater takes place. At the bottom of the ridge, the catchment becomes very flat, with an altitude between 3 and $5 \mathrm{~m}$ a.s.l. Here, the lithology consists of series of alternating marine sediments (clays, sandy clays) and fluvial deposits (coarse sands) overlain in the lowest areas by peat and clay deposits, also known as the covering layer (Huang, 2007) (Fig. 2). The low lying area constitutes a groundwater discharge area with seepage rates that have been estimated by Veldhuizen et al. (2009) at 1 to $2 \mathrm{~mm} / \mathrm{d}$ (annual average).

The surface drainage system of the study area is very dense as is typical in Dutch lowland areas. It consists of a set of canals and ditches that were designed to maintain appropriate groundwater levels according to the land use requirements. The water levels are kept as constant as possible, but they are kept slightly lower during winter times (about $0.1-0.3 \mathrm{~m}$ ), in order to create storage capacity in the channel network for potential winter floods caused by excessive rainfall. Control is achieved by the use of weirs and inlets. Weirs are control devices placed at different locations along the canals. Inlets are gate devices that let water flow into the study area. As typical in low lands, when floods take place water may leave the area at various points due to the flat topography (including change of flow directions).

\subsection{General methodological approach}

Understanding of the runoff generation process involves many aspects that can be summarized in three main steps: (i) familiarization with the physical environment where the processes take place e.g. hydrogeology, topography and surface drainage system, (ii) observation of different state variables at different locations e.g. groundwater levels, soil moisture, surface water levels and chemical/isotopic compositions etc., and (iii) formulation of a conceptual model of the water flow through the catchment and identification of the dominating runoff generation processes. Each of these steps may comprise activities at the catchment scale and at the local field scale. The activities at the catchment scale are necessary to gain insights on the hydrological heterogeneity of the area and its influence on the catchment scale responses. The work at the field scale contributes to the identification of the dominating runoff generation processes.

Base flow separation methods using various non-tracerbased methods and tracer-based methods applying different tracers should be carried out. The results of the non-tracerbased methods can be compared with the hydraulic and hydrological concept of the catchment and with the results of the tracer-based separations. The agreement or disagreement between the results of different methods provides further insights into their applicability to lowland areas and into the runoff generation processes at play. 

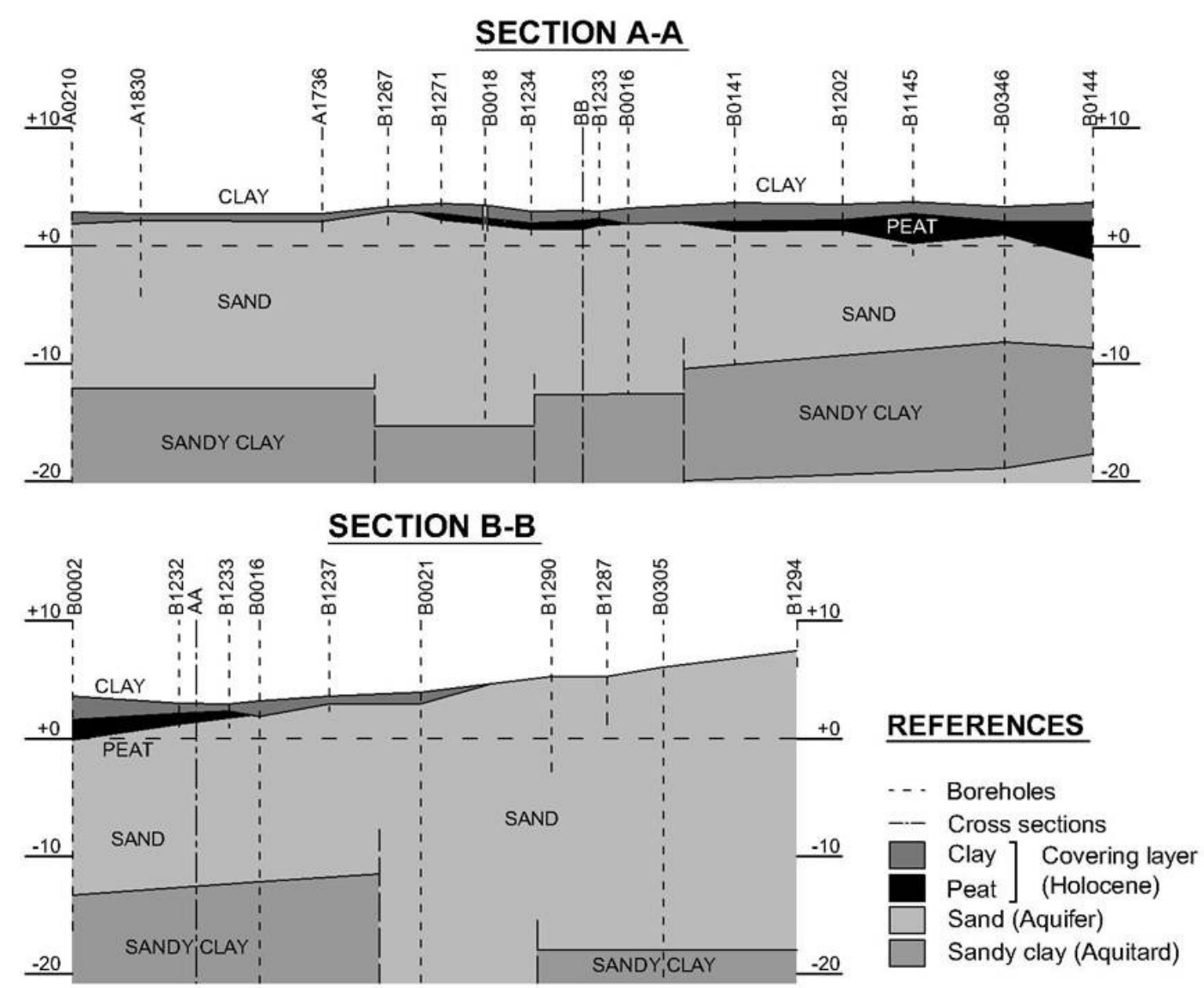

Fig. 2. Hydrogeological set-up of the study area, including typical cross sections and locations of exploration boreholes.

In this study, tracer-based hydrograph separation methods were compared with the following non-tracer-based methods: (i) simple graphical approach (Linsley et al., 1975), (ii) filtering methods (Sloto and Crouse, 1996), (iii) recursive filtering (Eckhardt, 2005), (iv) unit hydrograph method (Su, 1995), and (v) rating curve method (Sellinger, 1996; Kliner and Knezek, 1974). Each of these methods represents a different approach to base flow separation. Methods i and ii are classical methods frequently used in engineering applications. Method iii is a new recursive filtering method that improves its predecessors (see Eckhardt, 2005, for more details). Method iv is an alternative approach that reconstruct the base flow hydrograph raising limb with information of the recession limb. Method $\mathrm{v}$ takes advantage of the intrinsic relation between groundwater levels and base flow.

\subsection{Field and laboratory methods}

Field activities were carried out during the winter period from December 2007 up to March 2008. These activities include the drilling of observation wells, the collection and characterization of soil samples at different locations and depths, the set up of a groundwater monitoring network, and water sampling during floods and low flows.

\subsubsection{Meteorological and hydrometric data}

Hourly hydroclimatic data from the meteorological station in De Bilt were obtained from the KNMI, the Royal Meteorological Institute of The Netherlands. The station is located $18 \mathrm{~km}$ north-west of the study area. It can be assumed that these data are representative for the area since the geographical conditions are similar. Precipitation during the investigation period is dominated by advective rainfall events that have relatively low intensities and cover a wide area compared to convective events during summer.

Continuous discharge measurement of flows leaving the catchment and water inflows at the perimeter of the study area are carried out by the Water Board Stichtse Rijnlanden (HDSR) at the weirs and inlets used to control the levels in the area. For the purpose of this paper, the attention is focused on the discharges at the main outlet of the catchment which is controlled by weir W28 (see Fig. 1).

\subsubsection{Groundwater and surface water levels}

Groundwater levels were measured at nine observation wells. Four wells were used to observe the groundwater level behaviour at the catchment scale. Three of them were existing 


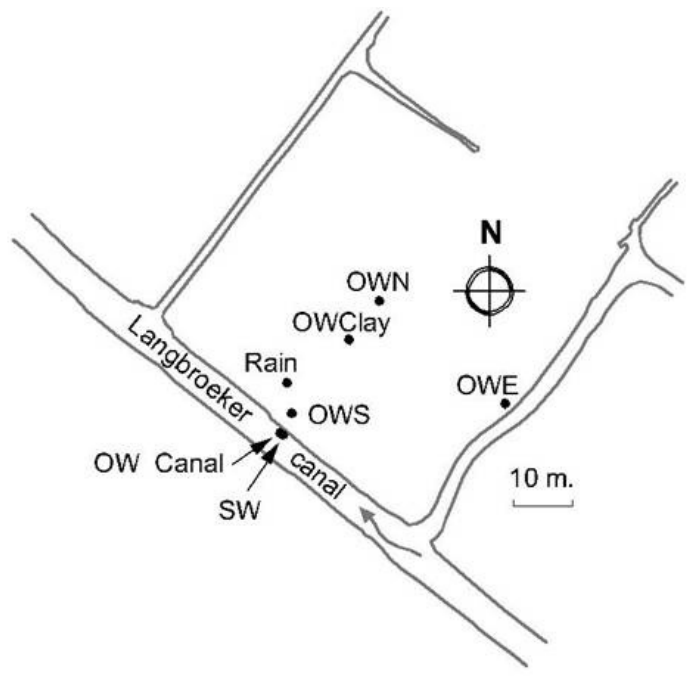

Fig. 3. Experimental field set-up and location of observation wells.

observation wells and one was installed in the clay layer (covering layer) next to an existing observation well (see Fig. 2 for cross sections). The other five wells were installed at an experimental field (approximately $3200 \mathrm{~m}^{2}$ ) that is surrounded by canals (Fig. 3). At this field groundwater discharge processes were studied at the field scale whereby one well was located in the covering clay layer (OWClay), three in the sandy aquifer right under the clay layer and one in the sandy aquifer under the Langbroekerwetering canal (OWCanal). To monitor the interactions of groundwater and surface water, surface water levels were also observed in the Langbroekerwetering canal, next to the experimental field. All these water level measurements were recorded with automatic data loggers (Divers), with a time step of $15 \mathrm{~min}$.

\subsubsection{Hydrochemistry and environmental isotopes}

Water chemistry was monitored during the research period by collecting water samples. The samples were taken at different stages of the water cycle: rainfall (one sample per event), ponded water, groundwater at the five observation wells at the experimental field (once per week), and at the main stream flow at the outlet of the catchment (time intervals: $4 \mathrm{~h}$ during the rising limb and shortly after the runoff peak and $8 \mathrm{~h}$ during recession periods).

Electric conductivity, $\mathrm{pH}$ and $\mathrm{HCO}_{3}^{-}$were measured in situ. Water samples were analyzed in the laboratory for major anions $\left(\mathrm{Cl}^{-}, \mathrm{NO}^{3-}\right.$ and $\left.\mathrm{SO}_{4}^{2-}\right)$ and major cations $\left(\mathrm{Na}^{+}\right.$, $\mathrm{K}^{+} \mathrm{Ca}^{2+}, \mathrm{Mg}^{2+}, \mathrm{Fe}^{2+}$ and $\mathrm{Mn}^{2+}$ ) using an ion chromatograph (ICS-1000, Dionex), and for dissolved silica $\left(\mathrm{SiO}_{2}\right)$ using a plasma ion chromatograph (Optima 3000, Perkin Elmer). The environmental isotopes deuterium and ${ }^{18} \mathrm{O}$ were analyzed using a mass spectrometer for a selected set of samples corresponding to the flood event from 31 January to 5 February.

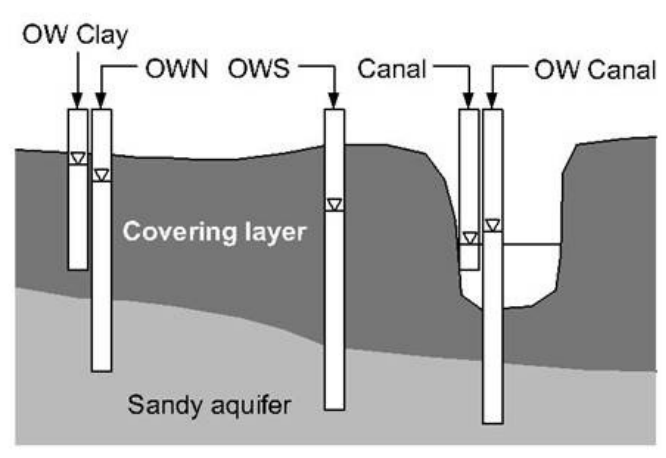

\subsection{Base flow separation methods}

\subsubsection{Runoff component separation using tracers}

To carry out tracer based component separation the hydrochemical and/or isotopic composition of the water is determined in order to identify the characteristic signature of water coming from different source areas and having different ages, e.g. deep groundwater, shallow groundwater, overland flow and precipitation. For doing a three-component separation an end member mixing analysis (EMMA; see Hooper et al., 1990; Christophersen et al., 1990) was carried out in order to define the hydrochemical signature of each component.

Assuming that the chemical composition of all investigated components is constant and significantly different, and that the mixing is conservative, the separation is calculated using the mass balance method by solving the following linear mixing equations:

$c_{i, 1} q_{1}+c_{i, 2} q_{2}+\cdots+c_{i, j} q_{j}+\cdots+c_{i, n} q_{n}=c_{i, T} q_{T}$

$q_{1}+q_{2}+\cdots+q_{j}+\cdots+q_{n}=q_{T}$

Where $c_{i, j}(\mathrm{ppm})$ is the concentration of solute $i$ in the flow component $j, c_{i, T}$ (ppm) is the concentration of solute $i$ in the total discharge $q_{T}\left(\mathrm{~m}^{3} / \mathrm{s}\right)$ measured at the outlet, and $q_{j}$ $\left(\mathrm{m}^{3} / \mathrm{s}\right)$ is the contribution of the flow component $j$ to the total discharge. The sum of all $q_{j}$ equals $q_{T}$. To separate $n$ different flow components, $(n-1)$ tracers are needed to solve the mixing equations. The method including its assumptions is widely discussed in the literature (e.g. Christophersen et al., 1990; Bonell, 1998; McDonnell and Tanaka, 2001; Joerin et al., 2002; Uhlenbrook and Hoeg, 2003). 


\subsubsection{Simple graphical approach}

Various approaches exist for performing graphical base flow separation; however, only one of them is applied in this study. To determine the end of the direct runoff contribution (usually assumed as surface runoff), the hydrograph is plotted on a semi-logarithmic scale and the groundwater recession curve can be identified as an approximately straight line, assuming groundwater flow can be approximated with the linear reservoir concept. It is assumed that the point where this line deviates from the hydrograph marks the end of the surface runoff, the hydrograph is from then on controlled by groundwater discharge (Linsley et al., 1975). A simple straight line of this point with the time at the beginning of the flood event (before surface runoff is noticeable) is used to separate the base flow during a flood event. The method is based on the assumption that the base flow response (which equals groundwater discharge) is significantly slower compared to the surface runoff, which is not always the case as shown in numerous case studies in mountainous areas (e.g. Bonell, 1998; McDonnell and Tanaka, 2001; Uhlenbrook and Hoeg, 2003).

\subsubsection{Filtering methods}

Pettyjhon and Henning (1979) formulated three base flow separation methods with the objective of processing long records of groundwater discharge data: (i) fixed interval (also known as Hysep 1), (ii) sliding interval (Hysep 2), and (iii) local minimum methods (Hysep 3), which are also called filtering separation methods. As explained in Sect. 1.1, these methods take the minimum values of the hydrograph within an interval by following different criteria and connect them. The discharge under the constructed line is defined as base flow accordingly (see Sloto and Crouse, 1996, for detailed description). The advantage of these methods is that they are standardized (objective) and systematic and, therefore, they can be easily translated into computer code to reduce the time required for computation and to avoid inconsistencies inherent to manual methods (Sloto and Crouse, 1996).

Pettyjohn and Henning (1979) and Sloto and Crouse (1996) defined the analysis interval size $2 N *$ used in these methods as the odd integer between 3 and 11 nearest to $2 N$ (with $N$ in days), where $N$ is the estimated time from the peak of the hydrograph to the end of the surface runoff according to Eq. (4) (equation proposed by Linsley et al., 1975). However, discharge time series may be presented with time steps other than days. This was the case for the study areas where very high resolution data is available and needed to account for the temporal dynamics. Therefore, for this study, the interval $2 N *$ is redefined as:

$2 N *=2\left\lfloor\frac{N}{\Delta t}\right\rfloor+1$

$N=0.8 A^{0.2}$ where $2 N *$ is the interval size in number of time steps, $N$ is the time from the peak of the hydrograph to the point where the direct runoff finishes in days, $A$ is the area of the catchment in square kilometers, and $\Delta t$ is the time step of the discharge's record in days/time step.

\subsubsection{Recursive filtering method}

Various methods of this type exist e.g. Lyne and Hollick (1979), Chapman (1991), Wittenberg (1999), Eckhardt (2005), Aksoy (2008), etc. In this study, the general approach proposed by Eckhardt (2005) is used to perform low pass filtering on the hydrograph in order to separate base flow (see Eq. 5). This recursive filter requires the determination of two parameters (Eckhardt, 2008): (i) the recession constant $a$, which can be derived from statistical analysis of the recession curves of the hydrograph, and (ii) the maximum value of the base flow index BFImax, which can not be measured, but optimized according to the results of other approaches (Eckhardt, 2005). In this research, BFImax was obtained by minimizing the root mean square deviations from the results of base flow separation using dissolved silica, which are believed to give a fair separation between groundwater and surface runoff. Note, that Eckhardt (2008) already suggested to use tracer data to calibrate the parameter BFImax, but the necessary data was not available for his study.

$b_{k}=\frac{\left(1-\mathrm{BFI}_{\max }\right) a b_{k-1}+(1-a) \mathrm{BFI}_{\max } y_{k}}{1-a \mathrm{BFI}_{\max }}$

Where $y_{k}\left(\mathrm{~m}^{3} / \mathrm{s}\right)$ is the total flow at time $k$ and $b_{k}\left(\mathrm{~m}^{3} / \mathrm{s}\right)$ is the base flow at time $k$, subject to $b_{k} \leq y_{k}$.

\subsubsection{Unit Hydrograph method}

This approach is based on the principle that an impulse input of recharged water into the subsurface system produces a response output in a similar way as an impulse of effective precipitation produces a response of surface runoff. Since the unit hydrograph is a model for a linear hydrologic system, its solutions follow the principles of proportionality and superposition ( $\mathrm{Su}, 1995)$. As proposed by Su (1995), the Nash's cascade reservoir model is used to represent mathematically the base flow unit hydrograph, where the groundwater watershed is represented by a series of $\varepsilon$ identical linear reservoirs, each of them having the same storage constant $k(\mathrm{~d})$. The actual base flow $Q_{(t)}\left(\mathrm{m}^{3} / \mathrm{s}\right)$ for a total recharge $R(\mathrm{~mm})$ can be written as:

$Q_{(t)}=R \frac{1}{k \Gamma(\varepsilon)}\left[\frac{t}{k}\right]^{\varepsilon-1} e^{-t / k}$

Or simply:

$Q_{(t)}=A t^{\theta} e^{\phi \cdot t}$

The parameters of the model $A\left(\mathrm{~m}^{3} / \mathrm{s}\right), \theta$ (dimensionless) and $\phi(1 / \mathrm{s})$ were determined by fitting the model using information from the recession limbs of the hydrograph. The fitted 
model was then used to construct the total base flow hydrograph, including the rising limbs.

\subsubsection{Rating curve method}

This method assumes that there is a relationship between groundwater levels and discharge in the stream during recession periods. Kliner and Knezek (1974) propose to determine this relation by fitting an envelope to all the available data from groundwater levels versus discharge measurements. Instead, Sellinger (1996) proposes to fit a curve only to the data corresponding to the recession limbs. Theoretically, both approaches should give similar results and for ease of calculation, the second approach was followed in this work. The potential relation that Sellinger (1996) proposes was not successful in this research. Therefore, the exponential function shown by Eq. (8) was applied with good results. The term $Q_{0}\left(\mathrm{~m}^{3} / \mathrm{s}\right)$ was introduced to account for a constant discharge coming from the deeper aquifer.

$Q=A e^{B h}+Q_{0}$

Where $Q\left(\mathrm{~m}^{3} / \mathrm{s}\right)$ is the discharge at the outlet of the catchment, $h(\mathrm{~m})$ is the groundwater level in an observation well, or an average groundwater level over the catchment, and $A$ $\left(\mathrm{m}^{3} / \mathrm{s}\right), B(1 / \mathrm{m})$ and $Q_{0}\left(\mathrm{~m}^{3} / \mathrm{s}\right)$ are fitting parameters, which can be determined e.g. with the least squares method using observed discharge $(Q)$ and water level data $(h)$ corresponding to the recession limb of the hydrograph after the surface runoff is over. The starting point of pure groundwater discharge may be determined approximately using Linsley's formula (see Eq. 4). The analysis has to be applied separately for each event.

\subsection{Response time of the aquifer system}

In order to fully analyse the runoff generation for the study area, it is also necessary to become familiar with the concept of the response time of an aquifer system. Assuming that in the study area the first aquifer under the covering layer is a confined aquifer, it is possible to calculate the time that an impulse, i.e. a recharge event at the upper boundary of the covering layer, takes to produce a maximum level rise at an observation well within the covering layer area. The following equations hold (they are also known as impulseresponse function) (Venetis, 1970; Olsthoorn, 2007):

$\Delta h_{(x, t)}=\Delta h_{(x=0, t=0)} \frac{u}{t \sqrt{\pi}} e^{-u^{2}}$

$u=\sqrt{\frac{x^{2} S}{4 k D t}}$

Where $\Delta h_{(x, t)}(\mathrm{m})$ is the increase in water level at a distance $x(\mathrm{~m})$ from the recharge area to an observation well in the area within the covering layer and at a time $t$ (d) since the occurrence of the impulse $\Delta h_{(x=0, t=0)}(\mathrm{m})$.

\section{Results}

\subsection{Rainfall runoff observations}

Figure 4 shows the precipitation, the discharge at the main outlet of the catchment (W28) and the water levels in the covering layer, in the first aquifer where the covering layer is not present (B343), $20 \mathrm{~m}$ from the canal (OWN), right under the canal (OWCanal), and in the canal itself (SW) at the experimental field during the research period. The measurements reveal an immediate response of the groundwater levels to the rainfall events and also a good correlation $\left(R^{2}=0.86\right)$ between groundwater levels in the first aquifer and discharges can be observed.

The observed groundwater levels also show that during the research period in winter 2008 rain water infiltrates and recharges the first aquifer (confined aquifer) since water levels in the covering clay layer at the experimental field (OWClay) are always higher than water levels in the first aquifer (OWN, OWS). However, recharge rates where the covering layer is present are likely to be small as a result of the compact clay separating the surface from the first aquifer. This can only happen with significant preferential flows trough the clay layer. On the other hand, more to the north, towards the Utrechtse Heuvelrug ice pushed ridge, where the compact clays are thin or non-existent, recharge into the first aquifer will be much larger. Water level observations also show that there is a permanent discharge of groundwater to the canals, in particular during floods. This is shown by the water levels in the canal (SW) being always lower than the groundwater levels in the first aquifer, right under the canal (OWCanal).

The changes in groundwater levels show a fast reaction to precipitation events. The fast reactions of groundwater levels in the first aquifer could be the result of water infiltration directly into the first aquifer at the northern boundary of the covering layer, which is displacing groundwater towards the canals in a piston flow process. Based on Eqs. (9) and (10) and considering an average length of the confined aquifer $(x)$ of $800 \mathrm{~m}$, an average thickness $(D)$ of $10 \mathrm{~m}$, and a saturated hydraulic conductivity $(k)$ of $30 \mathrm{~m} / \mathrm{d}$ and a storativity $(S)$ of $0.00137 \mathrm{~m} / \mathrm{m}$ (Saliha et al., 2004), a response time could be computed. Convolution of the impulse-response function for the precipitation event of 2 December results in a time to the peak of the response in the groundwater levels next to the canal of approximately $16 \mathrm{~h}(0.67 \mathrm{~d})$, which coincides with the delay of the reaction observed in the field. In the covering layer (OWClay) the peak of the groundwater head occurs later.

\subsection{Tracer-based two-component separation}

Electric conductivity (EC), calcium (Ca) and magnesium $(\mathrm{Mg})$ concentrations, on the one hand, and dissolved silica concentrations, on the other hand, were identified as suitable to perform two-component hydrograph separations. In 


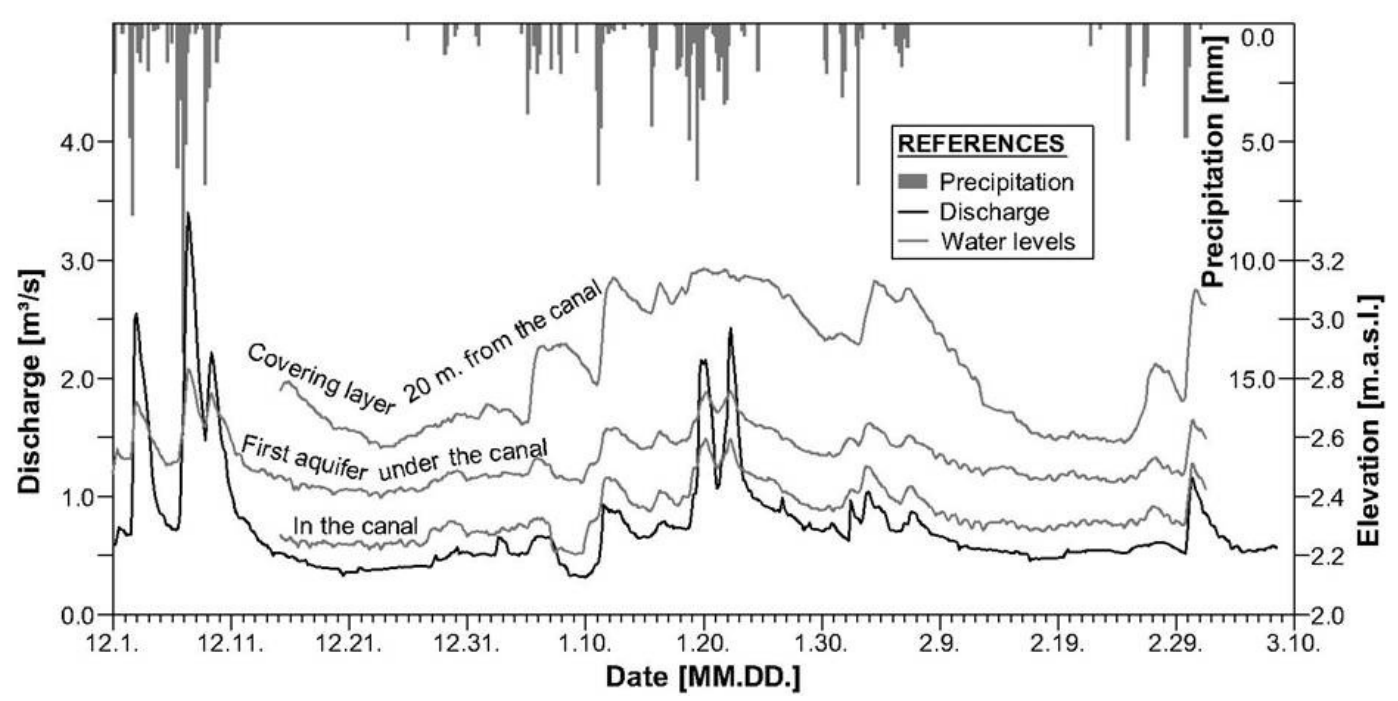

Fig. 4. Precipitation $(\mathrm{mm})(\Delta t=4 \mathrm{~h})$, discharge $\left(\mathrm{m}^{3} / \mathrm{s}\right)$ and ground and surface water levels $(\mathrm{m})$ observed during the research period.

both cases, the two separated components are surface runoff, composed of channel precipitation and overland flow, and groundwater contributions associated with deeper and older (pre-event) groundwater components.

\subsubsection{Two-component separation using EC, Ca and Mg}

The calcium concentrations of rainwater varied for each event, ranging from 0 to $5.7 \mathrm{mg} / \mathrm{L}$. They are low compared to the concentrations measured in groundwater and stream water. Therefore, an average concentration of $1.43 \mathrm{mg} / \mathrm{L}$ was used as the characteristic signature of surface runoff, assuming that the rainwater concentration is representative for this component. Calcium concentrations observed in wells showed variations in time and space, with values ranging between 55 and $120 \mathrm{mg} / \mathrm{L}$. These variations are probably the result of the geochemical heterogeneity of the area. The calcium concentrations at the outlet of the catchment (W28) varied between 33 and $70 \mathrm{mg} / \mathrm{L}$, They show an inverse relation with the discharge: a decrease with the increase of discharge and vice versa. Based on its typical concentration during low flow conditions, it can be concluded that the averaged calcium concentration of groundwater over the whole area of the catchment is around $67 \mathrm{mg} / \mathrm{L}$. Electric conductivity and magnesium show the same behavior as calcium, and the end member concentrations were estimated following a similar procedure. The separations based on these three tracers yielded similar results (see Fig. 5). It is observed that approximately $20 \%$ of the measured discharge corresponds to surface runoff.

\subsubsection{Two-component separation using dissolved silica $\left(\mathrm{SiO}_{2}\right)$}

Dissolution of silicate minerals is a slow process (e.g. Apello and Postma, 2005). Considering that the contact time of overland flow with the soil is short, it can be assumed that the dissolved silica concentration in overland flow does not change. Hence, it is assumed that the concentration of dissolved silica in surface runoff water is similar to the concentration in rain water which is negligible $(0.0 \mathrm{mg} / \mathrm{L})$. Concentrations of dissolved silica observed in groundwater varied between 5.0 to $15.0 \mathrm{mg} / \mathrm{l}$. The concentration observed in the stream, at the outlet of the catchment, during low flow periods $(5.5 \mathrm{mg} / \mathrm{l})$, is considered as a representative concentration of dissolved silica in groundwater. Two-component separation using dissolved silica shows that only a small amount of the discharge during floods at the outlet, in the order of $10 \%$, is surface runoff. The remainder is groundwater.

\subsection{Tracer-based three-component separation}

Construction of different EMMA diagrams with different hydrochemical and isotope tracers revealed that deuterium $\left(\delta^{2} \mathrm{H}\right)$ and magnesium $(\mathrm{Mg})$ are suitable tracers to perform three-component separation during the small event that took place during 1-5 February 2008. Note that deuterium data is only available for this period (see Fig. 6). The three end members that build up the flow can be attributed to surface runoff, shallow groundwater and deep groundwater. It is assumed that overland flow does not take up neither deuterium nor magnesium during the runoff generation processes and, therefore, the concentrations of these tracers in this component are similar to rain water: $-30.0 \%$ and $0.35 \mathrm{mg} / \mathrm{L}$. Thus, overland flow and rain water (directly falling to the 

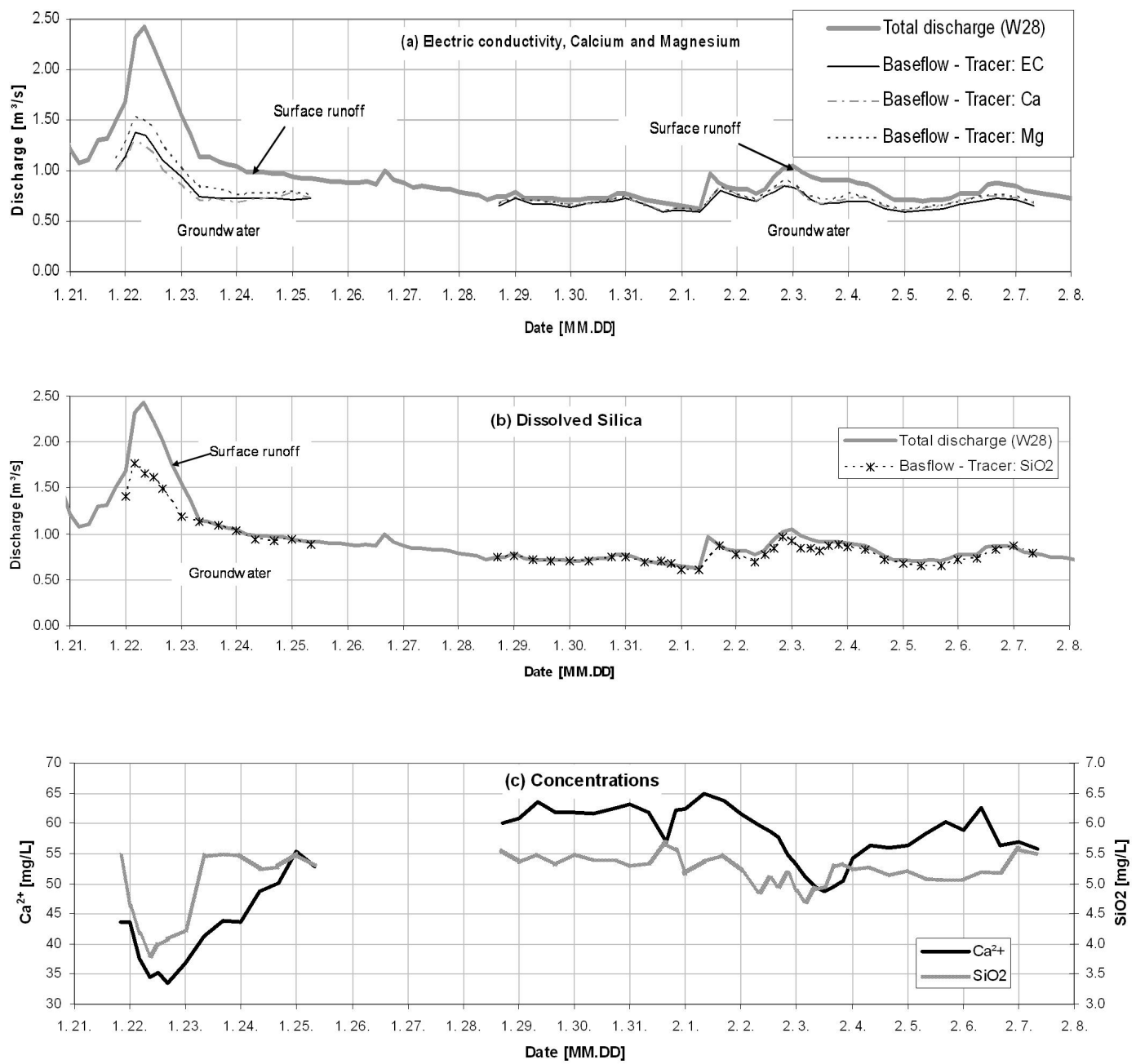

Fig. 5. Results of two-component separations using hydrochemical tracers. (a) surface runoff and groundwater separations using EC, Ca and $\mathrm{Mg}$ as tracers, (b) surface runoff and groundwater separation using dissolved silica, and (c) Calcium and dissolved silica concentrations measured in the stream at the outlet of the catchment $(\mathrm{mg} / \mathrm{L})$.

channel network) are considered as one component (surface runoff) during this tracer analysis. Deuterium was analyzed for only one deep groundwater sample $(-48.2 \%$ ) at OWCanal, the observation well positioned right under the canal. The concentration of magnesium in the deep groundwater component was determined as the concentration in the stream at the outlet of the catchment during recession periods: $8.10 \mathrm{mg} / \mathrm{l}$. Magnesium in groundwater samples varied from 6.3 to $16.4 \mathrm{mg} / \mathrm{l}$. It is assumed that a reasonable time after the precipitation event, shallow groundwater contribution to stream flow is zero or negligible. In the shallow groundwater component the end member concentrations were estimated as an average of the concentrations observed in the clay layer (OWClay): $-37.4 \%$ and $6.30 \mathrm{mg} / \mathrm{L}$.

Results of the separation reveal that the discharge peak is mainly produced by surface runoff and deep groundwater and to a lesser extent by shallow groundwater. The fast reaction of deep groundwater can be explained through mo- bilised groundwater that is displaced to the surface drainage system very likely by water infiltrating at the northern boundary of the covering layer in the catchment (see above). Furthermore, it can be observed that shallow groundwater shows a delayed reaction compared to surface runoff, which generates a shoulder (secondary peak) in the recession limb of the hydrograph. It is also worth noting, that surface runoff is slowly drained out of the catchment, being present as discharge component even some days after the rain event (see Fig. 7).

\subsection{Non-tracer-based hydrograph separation}

The components separated using non-tracer-based methods are called direct runoff and base flow to highlight that these methods not necessarily separate surface runoff and groundwater, as the two-component separations explained above, but usually, the fast and slow responses. The results of 

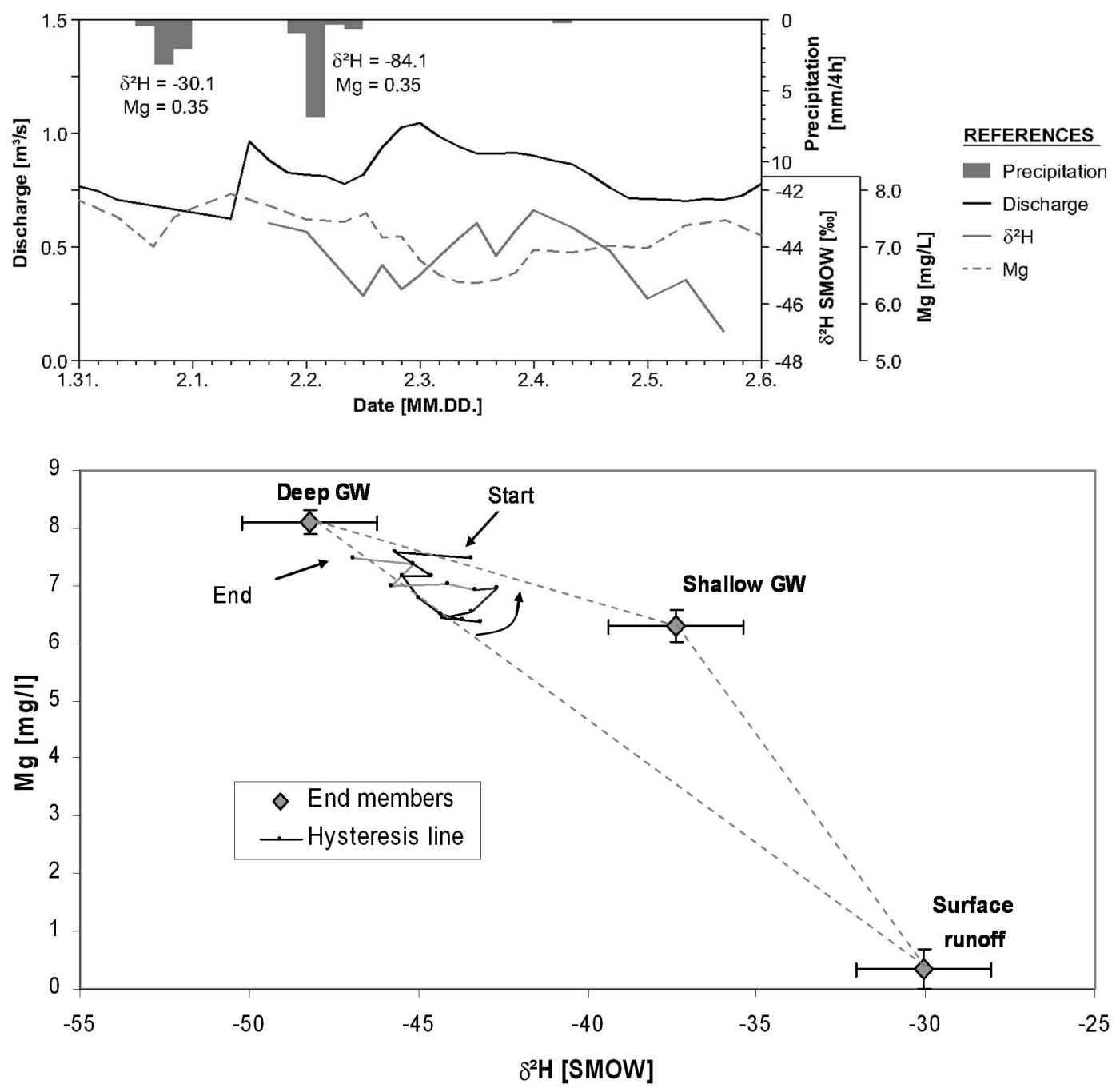

Fig. 6. End member analysis for three-component separation: (a) Precipitation, discharge and temporal variation of $\delta^{2} \mathrm{H}$ and $\mathrm{Mg}$ during the period between 1-5 February. (b) EMMA diagram for the three-component separation considering $\delta^{2} \mathrm{H}$ and $\mathrm{Mg}$ as tracers. The evolution of the concentrations in the stream is shown as a polygon with colour degradation from black to grey corresponding to the start and end respectively.

the different non-tracer-hydrograph separation methods are shown in Fig. 8. Each of them is compared to the twocomponent separation using dissolved silica as reference, which separates surface runoff from groundwater. For comparison purposes, the direct runoff ratio is defined as total direct runoff divided by the total discharge in the stream during the investigation period.

\section{Discussion}

Water level observations at the experimental field site revealed a fast groundwater reaction to the precipitation events in the studied lowland area. A simplified analysis of the reaction time in the first aquifer (see Sect. 3.1) shows that the reaction of the first aquifer may be related also to the recharge taking place in the northern part of the catchment, where the covering layer is thin or non existent. The calculated and observed times from the beginning of the event to the peaks of the groundwater levels are similar, assuming reasonable geometric parameters for the aquifer and confined conditions. Moreover, the increases of the groundwater levels in the covering layer occur later indicating that percolation through the covering layer is not causing the reaction in the first aquifer. A good correlation between water levels in the first aquifer and the discharge at the main outlet of the catchment is observed indicating that a significant part of the discharge in the drainage system is the result of the reaction in the first aquifer. These evidences indicate that groundwater is being displaced to the canals via a piston flow process, i.e. that recharge in the upper part of the catchment is pushing out groundwater at the discharge area. 


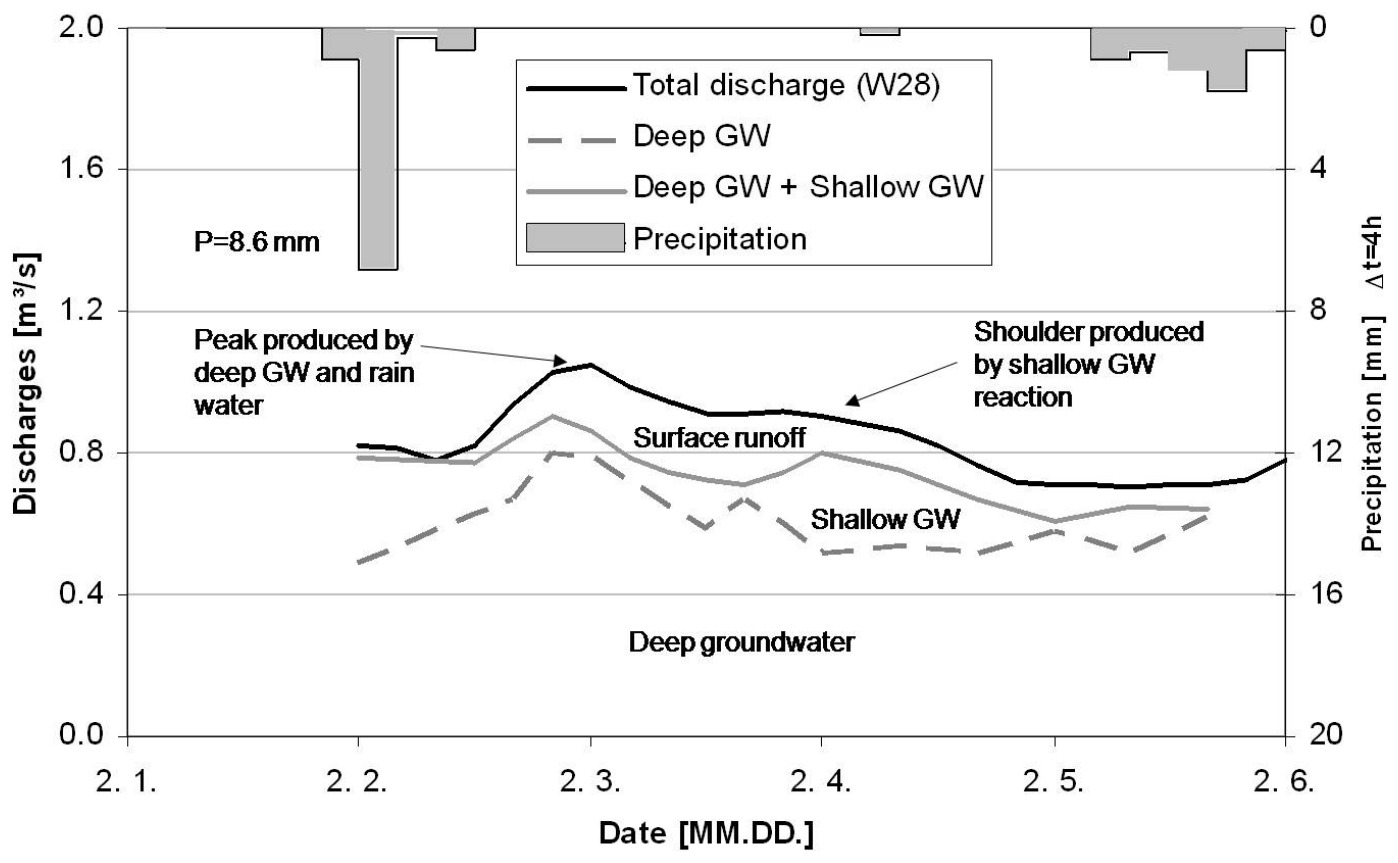

Fig. 7. Three-component separation considering $\mathrm{Mg}$ and $\delta^{2} \mathrm{H}$ as tracers.

Two-component tracer-based separations with dissolved silica, on the one hand, and using the hydrochemical tracers $\mathrm{EC}, \mathrm{Ca}$ and $\mathrm{Mg}$ on the other hand give results that are in line with the hydraulic investigations discussed above. Twocomponent separations using dissolved silica indicate that approximately $90 \%$ of the flow at the outlet of the catchment originates from groundwater, while separations using $\mathrm{EC}, \mathrm{Ca}$ and $\mathrm{Mg}$ point at an $80 \%$ of groundwater present in the total discharge. The approximately $10 \%$ difference between these two separations may be attributed to the uncertainties in the assessment of the end member concentrations. Within this frame, it is important to realize that dissolved silica is considered a largely conservative tracer (e.g. Uhlenbrook and Hoeg, 2003) while $\mathrm{EC}, \mathrm{Ca}$ and $\mathrm{Mg}$ are non-conservative tracers. Therefore, it is assumed that the separation performed with dissolved silica is more reliable. The $10 \%$ difference could also be attributed to the presence of different groundwater fluxes during the event, i.e. shallow versus deeper components that have different end members (see three-component separation). However, detailed water quality data along the depth of the aquifer are needed to prove this hypothesis.

The three-component separation also points at an important groundwater contribution, though the analysis could only be carried out for a relatively small event. Certainly, the deep groundwater peak resembles the deep groundwater water peak observed in the two-component separations confirming that groundwater is being displaced into the canals. Furthermore, it could be seen that shallow groundwater reaches the outlet later inducing a shoulder like shape into the hydrograph.
In the two-component separation with dissolved silica as well as in the three-component separation with $\delta^{2} \mathrm{H}$ and $\mathrm{Mg}$, it is assumed that overland flow takes up negligible amounts of the solutes which makes it possible to approximate its hydrochemistry with the one observed in rain water. This assumption is fair considering the slow kinetics of silica dissolution, the limited availability of Mg-sources on the soil surface, the conservative behaviour of deuterium, and the fact that mixing with other water at the surface seems negligible. However, a more detailed observation of the overland flow formation and its chemical composition is needed in future studies to verify these assumptions and to better understand the role of overland flow generation in such a low land.

All these physical parameter observations and tracer experiments show that groundwater is the main component of runoff in the studied lowland catchment. Generalization for all lowlands is not straight forward because there is a major role of the physical characteristics of the catchment (e.g. hydrogeology, land use, land cover). However, most lowland areas undergo similar geomorphological processes (e.g. sedimentation in alternating marine and fluvial environments), and it is possible to say that in most of them groundwater is likely to be the main component of runoff.

The single graphical approach (Linsley et al., 1975) and the filtering methods Hysep 1, 2 and 3 (Pettyjhon and Henning, 1979; Sloto and Crouse, 1996) give direct runoff ratios of 0.17 to 0.24 , which are higher compared to the separation using dissolved silica. The simplest method Hysep 1 gives the worst results; the others are closer to the tracer-based results, but do not really agree well with 


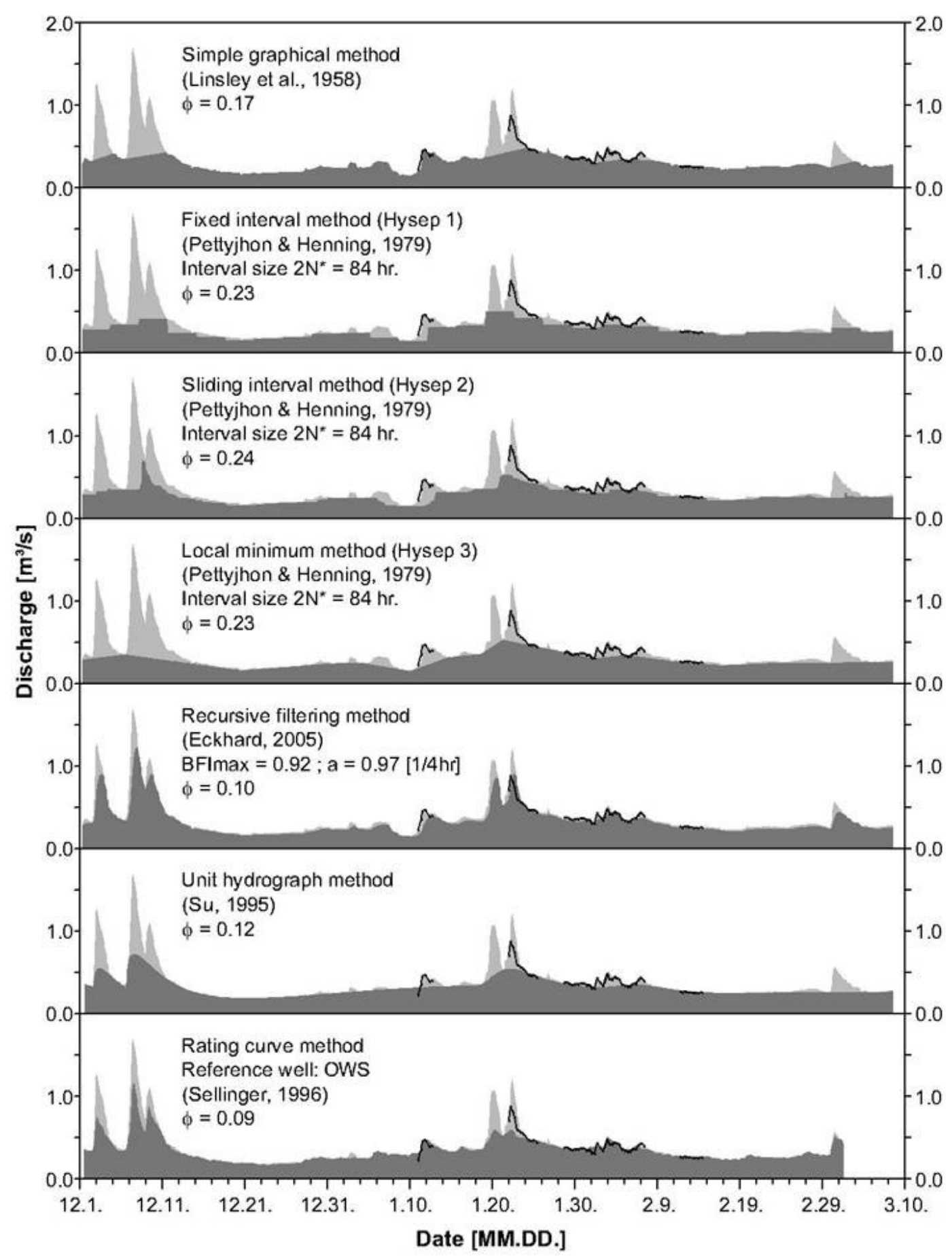

Fig. 8. Results obtained with different non-tracer based base flow separation methods and comparison with the surface runoff/groundwater separation using dissolved silica as tracer (black line); $\phi$ gives the mean direct runoff ratio defined as total direct runoff divided by the total discharge in the stream during the investigation period.

the benchmark separation technique. The unit hydrograph method $(\mathrm{Su}, 1995)$ resulted in a lower mean direct runoff ratio, 0.12. However, the results still do not represent the dynamic groundwater-surface runoff interactions as they can be observed in the separation using dissolved silica. Addition- ally, this method is subjective as the user has to decide about the number of events that are being modelled as groundwater response. The rating curve method showed a very acceptable direct runoff ratio of 0.08 . The method which is a more process based method, gives significantly better results. It 
does not only show that there is an important groundwater contribution during the flood events, but the separated base flow also follows the temporal course of the groundwater discharge obtained in the separation using dissolved silica. Finally, it can be observed that recursive filtering method (Eckhardt, 2005) gives the best results, if compared to the separation using dissolved silica, with a direct runoff ration of 0.10. This is not a surprise since the BFImax parameter of this method was calibrated with the results of the separation with dissolved silica, thus a good agreement of the two methods was expected.

\section{Conclusions}

The simplified analysis of the reaction time in the first aquifer, the good correlation observed between groundwater levels and discharges at the outlet of the catchment, and the tracer analyses (two and three component tracer-based separations), all of them indicate that groundwater displacement in a piston flow is the main process in runoff generation in the studied lowland. The importance of groundwater flow in runoff generation may be generalized to most flat lowland areas where topography and land use/cover do not favour surface runoff generation.

In general, tracer-based hydrograph separation methods agreed well with other field observations and proved to be useful to gain further insight in to the runoff generation processes in the studied lowland catchment. However, they may not be practical and economic in the long run and it is not possible to apply them to past discharge time series if no chemical/isotopic data of stream water and main source areas are available, which is usually the case. Therefore, it is necessary to use non-tracer-based base flow separation methods that still give meaningful insights in to the groundwater discharge of a catchment.

It was demonstrated that in the investigated lowland area, different non-tracer-based methods yield different separation results, which may be the case in most lowland areas. Consequently, the selection of an appropriate method is an important issue. Furthermore, the results show how tracer-based separations can be used to validate the results of the selected method. For the study area, the base flow separation method which identified the groundwater component of stream flow the best were the rating curve/envelope method (Sellinger, 1996; Kliner and Knezek, 1974) and the recursive filtering methods from Eckhardt (2005). The first method also gave good results in different mountainous areas (Kliner and Knezek, 1974; Holko et al., 2002). However, groundwater level measurements are needed for this method. The recursive filtering method provided in particular very satisfactory results when it was calibrated with the results of tracer investigations as suggested by Eckhardt (2005).

It is concluded that Eckhardt's recursive filtering method is suitable base flow separation in lowland areas when cali- bration of the BFImax parameter is performed with the use of tracer experiments. When groundwater level observations are available, the rating curve/envelope method is straight forward.

Finally, it was demonstrated that the results of verified non-tracer based methods can be used for estimating groundwater discharge in a low land catchment. This is essential, for instance, for groundwater or surface water model calibration/validation, water resources assessment etc. Future research will concentrate on these aspects with respect to the applicability to the hydrological conditions in low lands.

Acknowledgements. This study was supported by the Watermill Project of UNESCO-IHE and the Hoogheemraadschap de Stichtse Rijnlanden (HDSR), the Netherlands. Data for this research was kindly provided by the following institutions: HDSR (information on the study area and discharge time series), KNMI (hydroclimatic time series) and Vrije University of Amsterdam (analysis of water samples for the environmental isotopes deuterium and ${ }^{18} \mathrm{O}$ ).

Edited by: E. Zehe

\section{References}

Appelo, C. A. J. and Postma, D.: Geochemistry, groundwater and pollution, A.A. Balkema, 2005.

Aksoy, H., Unal, N. E., and Pektas, A. O.: Smoothed minima base?ow separation tool for perennial and intermittent streams, Hydrol. Processes, 22, 4467-4476, 2008.

Chapman, T. G.: Comment on "Evaluation of automated techniques for base ?ow and recession analyses" by R. J. Nathan and T. A. McMahon, Water Resour. Res., 27, 1783-1784, 1991.

Christophersen, N., Neal, C., and Hooper, R. P.: Modeling streamwater chemistry as a mixture of soil water endmembers, a step towards second generation acidification models, J. Hydrol., 116, 307-320, 1990.

Dingman, S. L.: Physical hydrology, Prentice Hall, 2002.

Eckhardt, K.: How to construct recursive digital filters for base flow separation, Hydrol. Processes, 19, 507-515, 2005.

Eckhardt, K.: A comparison of base flow indices, which were calculated with seven different base flow separation methods, J. Hydrol., 352, 168-173, 2008.

Hall, F. R.: Base-flow recessions - A review, Water Resour. Res., 4(5), 973-983, 1968.

Holko, L., Herrmann, A., Uhlenbrook, S., Pfister, L., and Querner, E.: Ground water runoff separation - test of applicability of a simple separation method under varying natural conditions. Friend 2002 - Regional hydrology: Bridging the gap between research and practice (IAHS Publication no. 274), 265-272, 2002.

Hooper, R. P., Christophersen, N., and Peters, J.: End member mixing analysis (EMMA): an analytical framework for the interpretation of streamwater chemistry, J. Hydrol., 116, 321-345, 1990.

Huang, C.: A conceptual validation framework for groundwater modeling. Case study Langbroekerwetering area. Water Science and Engineering - Hydrology and Water Resources, Delft, International Institute for Infrastructural, hydraulic and environmental engineering - Unesco-IHE, Master of Science: 130, 2007. 
Joerin, C., Beven, K. J., Iorgulescu, I., and Musy, A.: Uncertainty in hydrograph separations based on geochemical mixing models, J. Hydrol., 255(1-4), 90-106, 2002.

Kirchner, J. W., Feng, X., and Neal, C.: Fractal stream chemistry and its implications for contaminant transport in catchments, Nature, 403, 524-527, 2000.

Kirchner, J. W.: A double paradox in catchment hydrology and geochemistry, Hydrol. Processes, 17, 871-874, 2003.

Kliner, K. and Knezek, M.: The underground runoff separation method making use of the observation of ground water table, Hydrology and hydromechanics, XXII(5), 457-466, 1974.

Linsley, R. K., Kohler, M. A., and Paulhus, J. L. H.: Hydrology for engineers, McGraw-Hill, 1975.

Lyne, V. D. and Hollick, M.: Stochastic time-variable rainfall runoff modelling. Hydrology and Water Resources Symposium, Institution of Engineers Australia, Perth, 89-92, 1979.

McDonnell, J. J. and Tanaka, T. (Eds.): Hydrology and biogeochemistry of forested catchments, Special issue of Hydrological Processes, 15(9), 2001.

McGuire, K. J. and McDonnell, J. J.: A review and evaluation of catchment transit time modeling, J. Hydrol., 330, 543-563, 2006.

Olsthoorn, T. N.: Do a bit more with convolution, Groundwater, 46(1), 13-22, 2007.

Pettyjohn, W. A. and Henning, R.: Preliminary estimate of groundwater recharge rates, related streamflow and water quality in Ohio: Ohio State. University Water Resources Center, Project Completion Report Number 552, 323, 1979.

Saliha, A. H., Zhengyue, J., De Laat, P., and Nonner, J.: Modelling the Western Betuwe Area. Water Science and Engineering - Hydrology and Water Resources, Delft, International Institute for Infrastructural, Hydraulic and Environmental Engineering IHE. Master of Science: 155, 2004.

Sellinger, C. E.: Computer program for performing hydrograph separation using the rating curve method, US Department of Commerce, National Oceanic and Atmospheric Administration, Technical Memorandum ERL GLERL-100, 1996.

Sloto, R. A. and Crouse, M. Y.: HYSEP: A computer program for streamflow hydrograph separation and analysis, US Geological Survey, Water Resources Investigation Report, 96-4040, 1996.

$\mathrm{Su}, \mathrm{N} .:$ The unit hydrograph model for hydrograph separation, Environment International, 21(5), 509-515, 1995.
Szilagyi, J. and Parlange, M. B.: Base flow separation based on analytical solutions of the Boussinesq equation, J. Hydrol., 204(14), 251-260, 1998.

Tallaksen, L. M.: A review of base flow recession analysis, J. Hydrol., 165, 149-370, 1995.

Tardy, Y., Bustillo, V., and Boeglin, J. L.: Geochemistry applied to the watershed survey: hydrograph separation, erosion and soil dynamics. A case study: the basin of the Niger River, Africa, Appl. Geochemistry, 4, 469-518, 2004.

Uhlenbrook, S., Frey, M., Leibundgut, C., and Maloszewski, P.: Hydrograph separations in a mesoscale mountainous basin at event and seasonal timescales, Water Resour. Res., 38(6), 31-1/31-14, 2002.

Uhlenbrook, S. and Hoeg, S.: Quantifying uncertainties in tracerbased hydrograph separations: a case study for two three and five-component hydrograph separations in a mountainous catchment, Hydrol. Processes, 17, 431-453, 2003.

Uhlenbrook, S.: Catchment hydrology - a science in which all processes are preferential, Hydrol. Processes, HPToday, 20(16), 3581-3585, doi:10.1002/hyp.6564, 2006.

Uhlenbrook, S., Didszun, J., and Wenninger, J.: Source areas and mixing of runoff components at the hillslope scale - A multitechnical approach, Hydrol. Sci. J., 53(4), 741-753, 2008.

Veldhuizen, A. A., Heijkers, J., Borren, W., Nijsten, G. J., and Lagendijk, V.: HYDROMEDAH: Development of an integrated hydrological modelling toolkit \& database for Hoogheemraadschap De Stichtse Rijnlanden, in preperation, 2009 (in Dutch).

Venetis, C.: Finite aquifers: Characteristic responses and applications, J. Hydrol., 12(1-2), 53-62, 1970.

Weiler, M., Scherrer, S., Naef, F., and Burlando, P.: Hydrograph separation of runoff components based on measuring hydraulic state variables, tracer experiments, and weighting methods, IAHS Publications, 258, 249-255, 1999.

Weiler, M., McGlynn, B. L., McGuire, K. J., and McDonnell, J. J.: How does rainfall become runoff? A combined tracer and runoff transfer function approach, Water Resour. Res., 39(11), 4-1/4-13, 2003.

Wenninger, J., Uhlenbrook, S., Tilch, N., and Leibundgut, C.: Experimental evidence of fast groundwater responses in a hillslope/floodplain area in the Black Forest Mountains, Germany, Hydrol. Processes, 18(17), 3305-3322, 2004.

Wittenberg, H.: Baseflow recession and recharge as nonlinear storage processes, Hydrol. Processes, 13, 715-726, 1999. 